\title{
CURRENT DISTRIBUTIONS PRODUCED BY THE BANDED ELECTRODE ARRAY: AN EXPERIMENTAL STUDY CONDUCTED WITH A TANK MODEL
}

\author{
P. M. Lukies, BE; Y. C. Tong, BE, PhD; G. M. Clark, PhD, FRaCS
}

The tank model consisted of a 22-band electrode array lying in a homogeneous normal saline solution in the base of a tube $5 \mathrm{~mm}$ in diameter and $4 \mathrm{~cm}$ in length. The current distribution was obtained by measuring vector potentials along the longitudinal direction at a given radial distance from the electrode array. The results indicate that when only one pair of electrodes is stimulated, the current distribution is bell shaped. When two pairs are simultaneously stimulated by two isolated current sources, the results demonstrate a vector summation of current density throughout the system.

\section{METHODS}

The model consisted of a 22-band electrode array, each band being $0.6 \mathrm{~mm}$ in diameter, $0.3 \mathrm{~mm}$ in width, and separated from its adjacent band by $0.45 \mathrm{~mm}$, ' lying in the base of a tube $5 \mathrm{~mm}$ in diameter and $4 \mathrm{~cm}$ in length. The tube was filled with a homogeneous normal saline solution. ${ }^{2}$ A probe electrode, $25 \mu \mathrm{m}$ in diameter, was used to measure potential differences between the point at which the probe lies and a remotely situated gross reference electrode.

The probe was moved longitudinally along the array by a computer-controlled stepper motor, over a distance of 10 $\mathrm{mm}$, the potential difference between the probe and the remote electrode being measured every $0.1 \mathrm{~mm}$. Three runs of this type were initiated. The first run was done with the probe at a radial distance $r$, from the array. The radial distance of the probe from the array was then increased by $0.1 \mathrm{~mm}$ and the second run was initiated. For the third run, the probe was returned to the radial distance used for the first run, but was displaced perpendicular to the radial axis by $0.1 \mathrm{~mm}$. This allowed the collection of vector potentials in a three-dimensional grid.

Current density was then calculated in the following manner. Because the displacement between the points was a constant $0.1 \mathrm{~mm}$, the current density at any given point could be calculated as the resultant vector obtained by vector summation of the potential difference in the longitudinal direction, in the radial direction, and in the direction perpendicular to the radial axis. ${ }^{3}$

\section{RESULTS}

Results, in the form of current distributions, were obtained to investigate 1) the effects of different spacings between electrodes for single bipolar pair stimulation, and 2) simultaneous stimulation of two electrically isolated bipolar pairs of electrodes.

The results show that when interelectrode spacing is varied for stimulation of only one pair, the magnitude of the current distribution remains the same but the current spread is wider when broader interelectrode spacings are used. This provides explanations for psychophysical results observed. For instance, to achieve a comfortable loudness level, greater current levels are required for narrow interelectrode spacings than for broader interelectrode spacings. ${ }^{4}$ The reason for this is simply that to obtain the same current spread, more current is required for narrower interelectrode spacings.

Current distributions measured by simultaneously stimulating two pairs of electrodes in the tank model demon- strate a point-by-point vector summation of the current densities that would be obtained by independent stimulation of each of the individual pairs of electrodes. Theoretical vector summation considerations lead to the following expectations. As radial distance from the array is increased, in-phase stimulation would produce a current distribution that would demonstrate a notch in the region between the two pairs of electrodes, whereas out-of-phase stimulation would produce a bell-shaped current distribution. Increasing radial distance from the array further will demonstrate bell-shaped distributions for both in- and outof-phase stimulation, but the magnitude of the current distribution for in-phase stimulation will be greater than that for out-of-phase stimulation.

The results obtained from the tank validate these expectations. Brain stem evoked responses obtained from a cat with an intracochlear electrode array ${ }^{5}$ showed that the responses are greater in magnitude for in-phase stimulation than for out-of-phase stimulation. This is in agreement with the results obtained from the tank for radial distances greater than approximately $1 \mathrm{~mm}$ and therefore provides an estimate of the distance of the electrode array from the stimulated nerves.

\section{SUMMARY}

In conclusion, it is clear that this type of in vitro model is a useful tool when considering current distributions. Results suggest that when dealing with simultaneous stimulation of two electrically isolated bipolar pairs of electrodes, the current distribution demonstrates the effect of vector summation of the current densities of each electrode pair stimulated individually. These results also indicate the importance of knowing the distance between the array and the stimulated nerves when considering both complicated and simple forms of stimulus parameters.

\section{REFERENCES}

I. Clark GM, Patrick JF, Bailey QR. A cochlear implant round window array. J Laryngol Otol 1979;93:107-9.

2. Black RC, Clark GM, Patrick JF. Current distribution measurements within the human cochlea. IEEE Trans Biomed Eng $1981 ; 28: 721-5$

3. Hayt WH Jr. Engineering electromagnetics. 3rd ed. New York: McGraw-Hill, 1974:128-37.

4. Tong YC, Clark GM. Absolute identification of electric pulse rates and electrode positions by cochlear implant patients. J Acoust Soc Am 1985;77:1881-8.

5. Black RC, Clark GM, O'Leary SJ, Walters C. The auditory brainstem response in hearing and deaf cats evoked by intracochlear electrical stimulation. IUPS Satellite Symposium on Mechanisms of Hearing. Clayton, Victoria, Australia: Monash University Press, 1983: 153-7. 


\section{University Library}

\section{- M M N E R VA A gateway to Melbourne's research publications}

Minerva Access is the Institutional Repository of The University of Melbourne

Author/s:

Lukies, P. M.;Tong, Y. C.;Clark, Graeme M.

Title:

Current distributions produced by the banded electrode array: an experimental study conducted with a tank model

Date:

1987

\section{Citation:}

Lukies, P. M., Tong, Y. C., \& Clark, G. M. (1987). Current distributions produced by the banded electrode array: an experimental study conducted with a tank model. Annals of Otology, Rhinology \& Laryngology, 96(1, part 2, suppl.128), 24.

Persistent Link:

http://hdl.handle.net/11343/27253 